\title{
Interaction of Designed Sulfated Flavanoids with Antithrombin: Lessons on the Design of Organic Activators
}

\author{
Gunnar T. Gunnarsson and Umesh R. Desai* \\ Department of Medicinal Chemistry, Virginia Commonwealth University, 410 North 12th Street, P.O. Box 980540, \\ Richmond, Virginia 23298
}

Received March 25, 2002

\begin{abstract}
Recently, we designed (-)-epicatechin sulfate (ECS), the first small nonsaccharide molecule, as an activator of antithrombin for the accelerated inhibition of factor Xa, a key proteinase of the coagulation cascade (Gunnarsson, G. T.; Desai, U. R. J . Med. Chem. 2002, 45, 1233-1243). Although sulfated flavanoid ECS was found to bind antithrombin with an affinity $(\sim 10.7 \mu \mathrm{M})$ comparable to the reference trisaccharide DEF $(\sim 4.5 \mu \mathrm{M})$, it accel erated the inhibition of factor Xa only 10-fold as compared to the $\sim 300$-fold observed with DEF. To determine whether this conformational activation of the inhibitor is dependent on the structure of the organic activator and to probe the basis for the deficiency in activation, we studied the interaction of similar sulfated flavanoids with antithrombin. (+)-Catechin sulfate (CS), a chiral stereoisomer of ECS, bound plasma antithrombin with a 3-fold higher affinity $\left(\mathrm{K}_{\mathrm{D}}=3.5 \mu \mathrm{M}\right)$ and a 2-fold higher second-order rate constant for factor Xa inhibition $\left(k_{A C T}=6750 \mathrm{M}^{-1} \mathrm{~s}^{-1}\right)$. On the contrary, the $\mathrm{K}_{\mathrm{D}}$ and $\mathrm{K}_{\mathrm{ACT}}$ were found to be lower $\sim 7.4$ - and $\sim 2.4$-fold, respectively, for its racemic counterpart, $( \pm)$-catechin sulfate. Dependence of the equilibrium dissociation constant on the ionic strength of the medium at $\mathrm{pH} 6.0$ and 7.4 suggests that nonionic interactions contribute a major proportion ( $55-73 \%)$ of the total binding energy, and only $1-2$ ion pairs, in comparison to the expected $\sim 4$ ion pairs for the reference trisaccharide, are formed in the interaction. Competitive binding experiments indicate that activator CS does not compete with a saccharide ligand that binds antithrombin in the pentasaccharide binding site, while it competes with full-length low-affinity heparin. A molecular docking study suggests plausible binding of CS in the extended heparin binding site, which is adjacent to the binding domain for the reference trisaccharide DEF. In combination, the results demonstrate that although conformational activation of antithrombin with small sulfated flavanoids is dependent on the structure of the activator, the designed activators do not bind in the pentasaccharide binding site in antithrombin resulting in weak activation. The mechanistic investigation highlights plausible directions to take in the rational design of specific high-affinity organic antithrombin activators.
\end{abstract}

\section{Introduction}

Antithrombin, a member of the serpin family of proteins, is a major inhibitor of several proteinases, especially factor $\mathrm{Xa}$ and thrombin, which play pivotal roles in the clotting process. ${ }^{1,2}$ However, antithrombin alone is a rather poor inhibitor of these proteinases. Heparin, a naturally occurring sulfated linear polysaccharide, accelerates the antithrombin inhibition of the coagulation proteinases several $100-$ fol d $^{3,4}$ that forms the basis for polysaccharide's clinical use as an anticoagulant. Yet, the polymeric, polydisperse, polyanionic nature of heparin is the cause of many undesirable pathophysi ological consequences including hemorrhage, thrombocytopenia, osteoporosis, and inconsistent patient response.

A specific five residue sequence in heparin, called the DE F GH sequence (Figure 1), is involved in high-affinity binding to antithrombin. ${ }^{5,6}$ Mechanistically, the binding of pentasaccharide DEFGH (or polymeric heparin containing the DEFGH sequence) to antithrombin is an allosteric, two step, induced fit phenomenon in which the initial low-affinity recognition of the heparin binding

* To whom correspondence should be addressed. Tel: 804-828-8486. Fax: 804-828-7625. E-mail: urdesai@vcu.edu. domain is followed by a major conformational change in the inhibitor that results in the formation of a highaffinity activated complex. 7,8 This conformational change, which increases the affinity of the pentasaccharide DEFGH nearly 1000-fold, induces multidomain movements in the inhibitor including an increased exposure of a 15 residue protei nase recognition sequence containing the scissile bond, the so-called RCL.9,10 The conformational change phenomenon, also called antithrombin activation, is the reason for a 300-fold enhancement in the rate of factor $\mathrm{Xa}$ inhibition. ${ }^{8,10}$

Positively charged residues of helices $A$ and $D$ and the polypeptide $\mathrm{N}$ terminus comprise the heparin binding site in antithrombin. Pentasaccharide DEFGH has been shown to bind in the domain, the so-called PBS, ${ }^{11-15}$ formed by residues Arg47, Lys114, Lys125, and Arg129, while full-length heparin binds, in addition, to the extended region formed by residues Arg132, Lys133, and Argl36 at the C-terminal end of helix D, called the EHBS. ${ }^{16}$ The interaction of the carboxylate and sulfate groups of DEFGH with the positively charged residues of the PBS results in the transmission of binding energy to the RCL, a distance of nearly $20 \AA ., 9,11$ Studies with the truncated variants, trisaccharide DEF, and tetrasaccharide EFGH" (Figure 1 ) of the pentasaccharide 


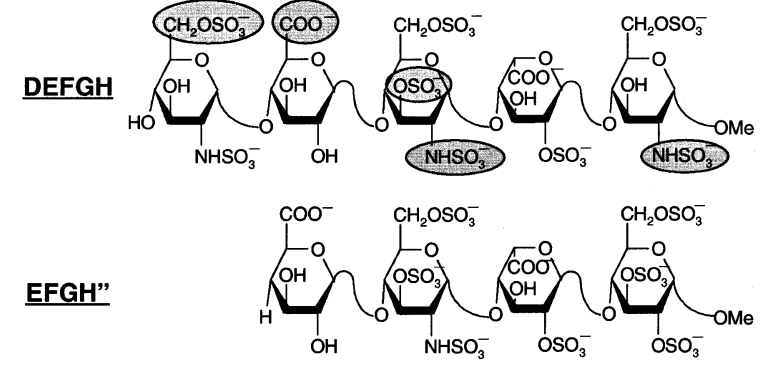

$(-)$-ECS

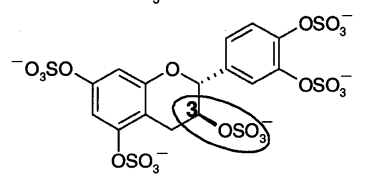

$(+)$-CS

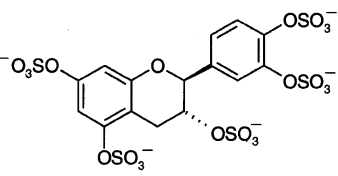

(-) -CS
Figure 1. Structures of oligosaccharide activators of antithrombin and sulfated flavanoids. DEFGH represents the specific pentasaccharide sequence in heparin that is important for anticoagulant activity. Circled residues in DEFGH are deemed critical for binding and activation of antithrombin under physiological conditions. Tetrasaccharide EFGH" is a structural variant that possesses equivalent activation potency as pentasaccharide DEFGH. Nonsaccharide small activator ECS was designed on the basis of a "pharmacophore" deduced from the four negatively charged moi eties in the DEF portion of the pentasaccharide. ECS possesses two chiral centers at the 2- and 3-positions. CS differs from ECS in the orientation of only one group, the sulfate at the 3-position. ( \pm )-CS or RCS is the racemic mixture of the (-)- and (+)-enantiomers of CS.

DEFGH indicate that the DEF sequence is critical for both the initial recognition and the conformational activation processes. ${ }^{17-19}$ In addition, synthetic trisaccharide DEF was found to activate antithrombin nearly 300-fol d, ${ }^{17}$ equival ent to the acceleration achieved with pentasaccharide DEFGH.

We reasoned that it should be possible to design small nonsaccharide ligands that bind antithrombin with high-affinity in the PBS and induce conformational activation in the inhibitor for accelerated inhibition of factor Xa. Using a combination of comparative molecular modeling and HINT, we designed ECS (Figure 1), a nonsaccharide organic sulfated flavan-3-ol molecule, to bind the PBS in antithrombin based on the trisaccharide DEF sequence. ${ }^{20} \mathrm{ECS}$ was found to bind antithrombin with an affinity comparable to DEF, as expected. F urthermore, ECS accelerated the antithrombin inhibition of factor Xa nearly 10-fold, the first small nonsugar organic mol ecule known to activate the inhibitor. However, the antithrombin activation achieved with ECS is small in comparison to nearly 300-fold observed, and targeted for, with trisaccharide DEF .

Sulfated flavanoid ECS is a dramatically different structure from the known saccharide activators and, hence, is exciting. In addition, it is synthetically accessible, while the natural saccharides are difficult to synthesize.6,21 More importantly, the first small organic activator may offer additional advantages, such as greater nonionic binding energy, and may provide important leads to the design of better high-affinity small activators. Thus, to gain insight into the phenomenon of activation by sulfated flavanoid ECS, we investigated its interaction with antithrombin at a molecular level using its derivatives. Our results demonstrate that although conformational activation of antithrombin with sulfated flavanoids is dependent on the structure of the organic activator, the activators do not interact with the PBS, contrary to our earlier prediction. Rather, they interact with the EHBS explaining the weaker-thanexpected activation. The mechanistic investigation highlights plausible directions to take in the rational design of specific, high-affinity, organic antithrombin activators.

\section{Materials and Methods}

Proteins and Chemicals. Human antithrombin, tetrasaccharide EFGH", and LAH $\left(M_{R} 7900 \pm 10 \%\right.$ Da) were a generous gift from Professor Steven $\mathrm{T}$. Olson of the University of Illinois-Chicago. Molar concentrations of the inhibitor were calculated from absorbance measurements at $280 \mathrm{~nm}$ using a $\epsilon_{\text {MAX }}$ of $37700 \mathrm{M}^{-1} \mathrm{~cm}^{-1}$. Human factor Xa was purchased from Haematologic Technologies (Essex J unction, VT) and was found to be more than $75 \%$ active. Factor Xa substrate Spectrozyme FXa was obtained from American Diagnostics, Greenwich, CT. (-)-E pi catechin, (+)-catechin, $( \pm)$-catechin, and TNS were purchased from Aldrich Chemical (Milwaukee, WI) and used without further purification. Triethylaminesulfur trioxide complex was prepared using the literature procedure. ${ }^{22}$

Nuclear Magnetic Resonance Spectroscopy. ${ }^{1} \mathrm{H}$ NMR spectra were recorded using a Varian $300 \mathrm{MHz}$ Gemini instrument at room temperature. The samples were dissolved in ${ }^{2} \mathrm{H}_{2} \mathrm{O}$ and lyophilized twice before the final dissolution in $500 \mu \mathrm{L}$ to give $\sim 10-25 \mathrm{mM}$ solution.

Experimental Conditions. Antithrombin interaction and activation studies were performed at $25^{\circ} \mathrm{C}$ and in $20 \mathrm{mM}$ sodium phosphate buffer, containing $0.1 \mathrm{mM}$ ethylenediaminetetraacetic acid (EDTA) and $0.1 \%(w / v)$ PEG 8000, adjusted to either $\mathrm{pH} 6.0$ or $\mathrm{pH}$ 7.4. The ionic strength of buffer in the absence of any added salt is either $0.025(\mathrm{pH} 6.0)$ or $0.035(\mathrm{pH}$ 7.4). Higher ionic strengths were achieved by adding $\mathrm{NaCl}$. Because of the reported decrease in stability of the inhibitor activity at lower $\mathrm{pH},{ }^{23}$ antithrombin solutions in $\mathrm{pH} 6.0$ buffer were prepared by fresh dilution from a stock solution at $\mathrm{pH}$ 7.4 (>100-fold). No significant losses in inhibitor activity were noted over the time frame of the experiments performed in this study.

Modeling Antithrombins. Sybyl 6.5 (Tripos Associates, St. Louis, MO) was used for computerized molecular modeling experiments. The structure of pentasaccharide-complexed antithrombin (accession number $1 a z x^{11}$ ) was acquired from RCSB. In the crystal structure, the inhibitor exists as a dimer of an inhibitory and a latent molecule. Chain I corresponding to the inhibitory monomer was extracted from the dimer and used as a model of the activated conformation. Residues 1, 2638, and 432 (1azx) are absent in the reported crystal structure. Previous biochemical studies do not implicate these absent amino acids in heparin binding; hence, the residues were not reengineered into the polypeptide chain. More importantly, the residues known to be important were present in the activated inhibitory polypeptide chain. Individual atoms were assigned Gasteiger-Hückel charges, and the polypeptide chain was minimized using the Tripos force field until a terminating gradient of $0.5 \mathrm{kcal} / \mathrm{mol} \AA^{2}$ was reached.

Modeling ECS and CS. The structures of ECS and CS (Figure 1) were built using the small molecule builder module in Sybyl 6.5. The global minimum energy conformation of each molecule was searched by systematic variation of bond angles in all of its rotatable bonds. The atom types for the oxygen atom in the $-\mathrm{SO}_{3}{ }^{-}$groups were modified to $\mathrm{O} . \mathrm{CO}_{2}{ }^{-}$so as to ensure that the bond angles and bond lengths of the simulated sulfate group were equivalent to that observed in the cocrystal 
structure of pentasaccharide-antithrombin complex. ${ }^{11}$ The partial charge for each atom in the pentasaccharide was computed using the Gasteiger-Hückel method. The protocol assigns a charge of -0.46 to the oxygens of the $\mathrm{SO}_{3}{ }^{-}$groups.

Docking. The flexidock module in Sybyl was used to dock the sulfated flavanoid on to the PBS or EHBS of the activated form of antithrombin. E ach molecule was prepositioned in the binding site, which was defined as residues within $4 \AA$ distance from Arg47, Lys114, Lys125, and Arg129 residues ${ }^{11}$ (PBS), or Arg132, Lys133, and Lys135 residues (EHBS). All basic amino acid residues lining the binding site were positively charged. Rotatable bonds of these residues were allowed conformational flexibility in the docking process, while the backbone and remaining bonds were held rigid. Water was excluded from the simulation, although a distance-dependent dielectric constant was used to simulate the presence of water.

Docking was performed with a rigid ligand model. No additional constraints, such as explicit formation of a hydrogen bond between selected donor-acceptor sites, were not introduced. In general, Flexidock provides nearly 20 solutions for each docking experiment. Comparative analyses suggested a single family of solutions for both the PBS and the EHBS with differences arising from changes in torsions of substituents on the flavanoid framework. It is likely that our use of nearly 300000 iterations of conformational search gradually enriched the most stable binding geometry resulting in a single family of orientation for each binding site. In this family of closely related structures, we chose the lowest energy binding mode because of the relative ease with which it could be further minimized to eliminate bad electronic and/or steric contacts.

Scoring. HINT (EduSoft LC, Ashland, VA) was used to evaluate the binding of sulfated flavanoids to antithrombin. HINT describes specific interactions between a small mol ecule and a macromolecule as a double sum over the atoms within each component. ${ }^{24,25}$

$$
\mathrm{B}=\sum_{\mathrm{i}=1}^{\text {atoms atoms }} \sum_{\mathrm{j}=1}^{\mathrm{b}_{\mathrm{ij}}}=\sum \sum\left(\mathrm{S}_{\mathrm{i}} \mathrm{a}_{\mathrm{i}} \mathrm{S}_{\mathrm{j}} \mathrm{a}_{\mathrm{j}} \mathrm{R}_{\mathrm{ij}} \mathrm{T}_{\mathrm{ij}}+\mathrm{r}_{\mathrm{ij}}\right)
$$

where $\mathrm{S}$ is the solvent accessible surface area, a is the hydrophobic atom constant, $\mathrm{T}$ is a descriptor function, and $\mathrm{R}$ and $r$ are functions of the distance between atoms $i$ and $j$. F rom this equation, a binding score is calculated where $b_{i j}$ describes the specific interaction between atoms $i$ and $j$ and $B$ describes the total interaction score between the two species. A detailed description of the HINT interaction analysis can be found in refs $24-26$.

Antithrombin was assigned HINT parameters from a dictionary of previously determined values. Only polar hydrogens were explicitly used in the partitioning of the protein and the ligand, following which an interaction score using eq I was cal culated for the docked complex. Because HINT parameters for the sulfur atoms in higher oxidation states including sulfates are not well-established, these scores were el iminated. Three-dimensional HINT maps that pictorially represent the noncovalent interactions were calculated on a $1 \AA$ grid.

Synthesis and Characterization of ECS, CS, and RCS. ECS, CS, and RCS were synthesized from (-)-epicatechin, (+)catechin, and $( \pm)$-catechin, respectively, by sulfation with triethylamine-sulfur trioxide complex (Scheme 1) at $65^{\circ} \mathrm{C}$ in dimethylacetamide. ${ }^{27} \mathrm{~F}$ ollowing the reaction, the mixture was poured into acetone under basic conditions and left for $24 \mathrm{~h}$ at $4{ }^{\circ} \mathrm{C}$. The crude oil formed at the bottom was washed with acetone and suspended in $30 \%$ sodium acetate. The suspension was added to ethanol to precipitate the sodium salt of the sulfate molecule.

The concentration of the sulfated flavanoid was estimated from its weight and confirmed by its extinction coefficient at $277 \mathrm{~nm}\left(\epsilon_{277}=4200 \mathrm{M}^{-1} \mathrm{~cm}^{-1}\right.$ (ECS) and $3890 \mathrm{M}^{-1} \mathrm{~cm}^{-1}$ (CS and RCS)). Micellar electrokinetic capillary el ectrophoresis (20 $\mathrm{mM}$ sodium borate buffer containing $100 \mathrm{mM}$ sodium dodecyl sulfate (SDS), pH 8.0, at $30 \mathrm{kV})^{28}$ with UV detection at 277 nm showed a single peak suggesting high purity of the sulfated flavanoid. The IR spectra of each sulfated product indicated a

\section{Scheme 1}

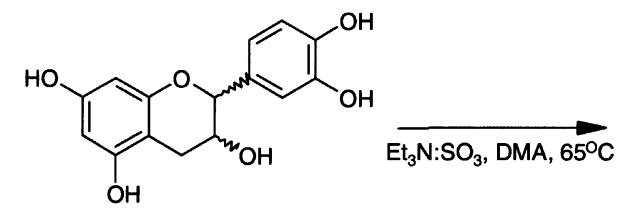<smiles>COc1cc(O[Na])c2c(c1)O[C@@H](c1ccc(OC(=O)[O-])c(OC(=O)[O-])c1)[C@@H](OS(=O)(=O)[O-])C2</smiles>

strong band in the region of $1250-1260 \mathrm{~cm}^{-1}$, characteristic of $-\mathrm{SO}_{3}{ }^{-}$stretch vibrations. A comparison of the $300 \mathrm{MHz}{ }^{1} \mathrm{H}$ NMR spectra of the starting flavanoid and the sulfated product in each case shows a downfield shift of $0.5-0.9 \mathrm{ppm}$ for all protons suggesting sulfation of all available hydroxyl groups. Elemental analysis of repeatedly precipitated sulfated product indicated the presence of $\mathrm{H}_{2} \mathrm{O}$ and $\mathrm{Na}_{2} \mathrm{SO}_{4}$ molecules. ECS: ${ }^{1} \mathrm{H}$ NMR $\left({ }^{2} \mathrm{H}_{2} \mathrm{O}\right): \delta 3.10\left(\mathrm{dd}, 1 \mathrm{H},{ }^{2} \mathrm{~J}=18 \mathrm{~Hz},{ }^{3} \mathrm{~J}=4.2 \mathrm{~Hz}, \mathrm{Ar}-\right.$ $\left.\mathrm{CH}_{2}\right), 3.45\left(\mathrm{dd}, 1 \mathrm{H}, 2 \mathrm{j}=18 \mathrm{~Hz}, 3 \mathrm{j}=6 \mathrm{~Hz}, \mathrm{Ar}-\mathrm{CH}_{2}\right), 5.00(\mathrm{~m}$, $\left.1 \mathrm{H}, \mathrm{CH}-\mathrm{OSO}_{3}{ }^{-}\right), 5.10(\mathrm{~d}, 1 \mathrm{H}, 3 \mathrm{~J}=8.1 \mathrm{~Hz}, \mathrm{O}-\mathrm{CH}-\mathrm{Ar}), 6.80-$ $7.70(\mathrm{~m}, 5 \mathrm{H}, \mathrm{Ar})$. Elemental analysis calcd (\%) for $\mathrm{C}_{15} \mathrm{H}_{9} \mathrm{O}_{21} \mathrm{~S}_{5-}$ $\mathrm{Na}_{5}+6 \mathrm{H}_{2} \mathrm{O}+0.5 \mathrm{Na}_{2} \mathrm{SO}_{4}: \mathrm{C}, 17.9 ; \mathrm{H}, 2.1 ; \mathrm{S}, 17.8$. Found (\%): C, 17.29; $\mathrm{H}, 2.21 ; \mathrm{S}, 18.00$. CS: ${ }^{1} \mathrm{H}$ NMR $\left({ }^{2} \mathrm{H}_{2} \mathrm{O}\right): \delta 3.15$ (dd, $\left.1 \mathrm{H},{ }^{2} \mathrm{~J}=17.4 \mathrm{~Hz}, 3 \mathrm{~J}=4.8 \mathrm{~Hz}, \mathrm{Ar}-\mathrm{CH}_{2}\right), 3.6\left(\mathrm{dd}, 1 \mathrm{H},{ }^{2} \mathrm{~J}=17.4\right.$ $\left.\mathrm{Hz}, 3 \mathrm{j}=7.2 \mathrm{~Hz}, \mathrm{Ar}-\mathrm{CH}_{2}\right), 5.0\left(\mathrm{~m}, 1 \mathrm{H}, \mathrm{CH}-\mathrm{OSO}_{3}{ }^{-}\right), 5.15(\mathrm{~d}, 1 \mathrm{H}$, $3 \mathrm{~J}=4.5 \mathrm{~Hz}, \mathrm{O}-\mathrm{CH}-\mathrm{Ar}), 6.90-7.60(\mathrm{~m}, 5 \mathrm{H}, \mathrm{Ar})$. Elemental analysis calcd (\%) for $\mathrm{C}_{15} \mathrm{H}_{9} \mathrm{O}_{21} \mathrm{~S}_{5} \mathrm{Na}_{5}+9 \mathrm{H}_{2} \mathrm{O}+0.0 \mathrm{Na}_{2} \mathrm{SO}_{4}$ : C, 18.7; H, 2.8; S, 16.7. Found (\%): C, 18.87; H, 2.96; S, 16.36 . RCS: ${ }^{1} \mathrm{H}$ NMR $\left({ }^{2} \mathrm{H}_{2} \mathrm{O}\right): \delta 3.15\left(\mathrm{~m}, 1 \mathrm{H}, \mathrm{Ar}-\mathrm{CH}_{2}\right), 3.6(\mathrm{~m}, 1 \mathrm{H}$, $\left.\mathrm{Ar}-\mathrm{CH}_{2}\right), 5.0\left(\mathrm{~m}, \mathrm{H}, \mathrm{CH}-\mathrm{OSO}_{3}{ }^{-}\right), 5.20(\mathrm{~m}, \mathrm{HH}, \mathrm{O}-\mathrm{CH}-\mathrm{Ar}), 6.90-$ $7.50(\mathrm{~m}, 5 \mathrm{H}, \mathrm{Ar})$. E lemental analysis calcd (\%) for $\mathrm{C}_{15} \mathrm{H}_{9} \mathrm{O}_{21} \mathrm{~S}_{5-}$ $\mathrm{Na}_{5}+8 \mathrm{H}_{2} \mathrm{O}+3.0 \mathrm{Na}_{2} \mathrm{SO}_{4}: \mathrm{C}, 13.1 ; \mathrm{H}, 1.9 ; \mathrm{S}, 18.6$. F ound (\%): C, 12.88; H, 1.81; S, 17.97 .

Fluorescence Spectroscopy and Equilibrium Binding Studies. Fluorescence experiments were performed with a PCI Spectrofluorometer (ISS I nstruments, Champaign, IL) at room temperature. Equilibrium dissociation constants $\left(K_{D}\right)$ for the interaction of sulfated flavanoid with plasma antithrombin were determined by titrating the sulfated flavanoid into a solution of antithrombin-TNS complex and monitoring the decrease in the fluorescence at $432 \mathrm{~nm}\left(\lambda_{\mathrm{Ex}}=330 \mathrm{~nm}\right)$. The decrease in fluorescence signal was fit to the quadratic equilibrium binding eq II to obtain the $K_{D}$ of interaction, wherein $\Delta \mathrm{F}$ represents the change in fluorescence following each addition of the activator ([ACT $\left.]_{0}\right)$ from the initial fluorescence $F_{O}$ and $\Delta F_{M A X}$ represents the maximal change in fluorescence observed on saturation of antithrombin ([AT $\left.]_{0}\right)$. Sufficient signal intensity was obtained with $1 \mu \mathrm{M}$ AT and 5 $\mu \mathrm{M}$ TNS.

$$
\begin{aligned}
\frac{\Delta \mathrm{F}}{\mathrm{F}_{\mathrm{O}}}= & \frac{\Delta \mathrm{F}_{\mathrm{MAX}}}{\mathrm{F}_{\mathrm{O}}} \times\left[\left([\mathrm{AT}]_{\mathrm{O}}+[\mathrm{ACT}]_{\mathrm{O}}+\mathrm{K}_{\mathrm{D}}\right)-\left\{\left([\mathrm{AT}]_{\mathrm{O}}+\right.\right.\right. \\
& {\left.\left.\left.[\mathrm{ACT}]_{\mathrm{O}}+\mathrm{K}_{\mathrm{D}}\right)^{2}-4 \times[\mathrm{AT}]_{\mathrm{O}}[\mathrm{ACT}]_{\mathrm{O}}\right\}^{1 / 2}\right] / 2 \times[\mathrm{AT}]_{\mathrm{O}}(\mathrm{II}) }
\end{aligned}
$$

Competitive Binding of CS in the Presence of Tetrasaccharide EF GH" or LAH. Antithrombin binding to CS in the presence of EFGH" or LAH was performed at a fixed concentration of the competitor by monitoring the decrease in TNS fluorescence as a function of increasing CS concentration at $25{ }^{\circ} \mathrm{C}$. Titrations were performed at either $\mathrm{pH} 6.0, \mathrm{I} 0.025$ $\left(E F G H^{\prime \prime}\right)$ or $\mathrm{pH} 7.4, \mathrm{I} 0.035(\mathrm{LAH})$. The concentrations of the competitor chosen ranged from 0.67 to $6.7 \times \mathrm{K}_{\mathrm{D}}$ of the competitor-antithrombin interaction and were much greater than the concentration of antithrombin $(<0.75 \mu \mathrm{M})$. The decrease in fluorescence was analyzed in the same manner as 
Table 1. Overall HINT Score, Equilibrium Dissociation Constant, Free Energy of Binding, and the Second-Order Factor Xa Inhibition Rate Constant for the Interaction of Sulfated Flavanoids with Plasma Antithrombina

\begin{tabular}{|c|c|c|c|c|c|c|c|}
\hline & \multirow[b]{2}{*}{ overall HINT score } & \multicolumn{2}{|c|}{$\mathrm{K}_{\mathrm{D}, \mathrm{OBS}}(\mu \mathrm{M})$} & \multicolumn{2}{|c|}{$\Delta \mathrm{G}^{\circ}(\mathrm{kcal} / \mathrm{mol})$} & \multirow{2}{*}{$\frac{\mathrm{k}_{\mathrm{ACT}}\left(\mathrm{M}^{-1} \mathrm{~S}^{-1}\right)}{\mathrm{pH} 6.0}$} & \multirow{2}{*}{$\frac{\text { acceleration }}{\mathrm{pH} 6.0}$} \\
\hline & & $\mathrm{pH} 6.0$ & $\mathrm{pH} 7.4$ & $\mathrm{pH} 6.0$ & $\mathrm{pH} 7.4$ & & \\
\hline $\begin{array}{l}(-) \text {-ECS } \\
(+)-C S \\
( \pm)-C S\end{array}$ & $\begin{array}{l}3687 \\
3556 \\
b\end{array}$ & $\begin{array}{r}10.7 \pm 1.1 \\
3.5 \pm 0.5 \\
26.1 \pm 1.6\end{array}$ & $\begin{array}{l}32.3 \pm 3.3 \\
17.9 \pm 1.6\end{array}$ & $\begin{array}{l}6.8 \pm 0.1 \\
7.5 \pm 0.2 \\
6.3 \pm 0.1\end{array}$ & $\begin{array}{l}6.2 \pm 0.1 \\
6.5 \pm 0.1\end{array}$ & $\begin{array}{l}3380 \pm 215 \\
6750 \pm 475 \\
2770 \pm 170\end{array}$ & $\begin{array}{r}10.4 \pm 1.5 \\
20.8 \pm 3.1 \\
8.5 \pm 1.2\end{array}$ \\
\hline
\end{tabular}

a The overall HINT score was determined by docking and scoring the simulated complexes. The $\mathrm{K}_{\mathrm{D}}$ was determined from the decrease in the fluorescence of the bound TNS following interaction of the activator with plasma antithrombin at $25^{\circ} \mathrm{C}$ in $20 \mathrm{mM}$ sodium phosphate buffer at either $\mathrm{pH} 6.0$ or $\mathrm{pH} 7.4$ and at $25^{\circ} \mathrm{C}$ assuming a 1:1 binding stoichiometry. The second-order rate constant $\left(\mathrm{k}_{\mathrm{ACT}}\right)$ for antithrombin inhibition of factor $\mathrm{Xa}$ in the presence of the activator was determined in pH 6.0 buffer at $25^{\circ} \mathrm{C}$. The second-order rate constant (kunCaT) for inhibition of factor $\mathrm{Xa}$ by antithrombin al one was determined independently under identical conditions and found to be $325 \pm 25 \mathrm{M}^{-1}$

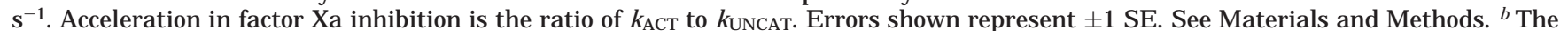
overall HINT score for (-)-CS interacting with antithrombin in the PBS was 3692. Because it is a racemic mixture, the HINT score for $( \pm)$-CS is not listed in the table.

above using eq II to obtain the apparent equilibrium dissociation constant, $K_{C S, A P P .}$

Dependence of the Observed Equilibrium Dissociation Constant of Interaction on the Ionic Strength of the Medium. The dependence of the observed dissociation constant $\left(K_{D, O B S}\right)$ on the ionic strength $(I)$ of the medium was determined by titrating plasma antithrombin with the sulfated flavanoid in either $\mathrm{pH} 6.0$ or $\mathrm{pH} 7.4$ buffer in the presence of varying $\mathrm{NaCl}$ concentrations using the external probe, TNS. The data were fit to eq III, where $K_{D, N O N I O N I C}$ is the saltindependent dissociation constant, $Z$ is the total number of ionic interactions involved in the association of the protein with heparin, and $\Psi$ is the fraction of monovalent counterion bound per activator ionic charge that is released on protein binding and has a value of $0.8 .^{29}$ The slope gives the number of ionic interactions formed on activator binding to antithrombin, while the contribution of nonionic interactions can be obtained from the intercept.

$$
\log \mathrm{K}_{\mathrm{D}, \mathrm{OBS}}=\log \mathrm{K}_{\mathrm{D}, \mathrm{NONIONIC}}+\mathrm{Z} \psi \log \left[\mathrm{Na}^{+}\right]
$$

Factor Xa Inhibition Studies. The kinetics of inhibition of factor $\mathrm{Xa}$ by antithrombin alone was determined spectrophotometrically following literature procedures. ${ }^{30}$ The kinetics of the antithrombin inhibition of factor $\mathrm{Xa}$ in the presence of sulfated flavanoids, ECS, CS, and RCS was measured under pseudo-first-order conditions. A fixed $10 \mathrm{nM}$ concentration of factor Xa was incubated with plasma antithrombin (1 mM) and the sulfated flavanoid $(0-50 \mathrm{mM})$ in $\mathrm{pH} 6.0$ buffer at 25 ${ }^{\circ} \mathrm{C}$. After it was incubated for $10 \mathrm{~min}$, the reactions were quenched with $900 \mathrm{~mL}$ of $100 \mathrm{mM}$ Spectrozyme FXa in $20 \mathrm{mM}$ sodium phosphate buffer, containing $100 \mathrm{mM}$ sodium chloride, $0.1 \mathrm{mM}$ EDTA, and 0.1\% (w/v) PEG 8000, at pH 7.4. The residual factor $\mathrm{Xa}$ activity was then measured spectrophotometrically from the initial rate of substrate hydrolysis at 405 $\mathrm{nm}$. The second-order rate constant of factor $X a$ inhibition $\left(\mathrm{K}_{\mathrm{ACT}}\right.$ ) was determined using eq IV (This equation was deduced from pseudo-first-ordered reaction equation $\mathrm{T}=\mathrm{T}_{\mathrm{O}} \exp \left(-\mathrm{k}_{\mathrm{OBs}}\right.$ $x \mathrm{t})$ for single turnover kinetics in the presence $\left(\mathrm{T}_{2}, \mathrm{~K}_{\mathrm{OBS}}=\right.$ $\left.\mathrm{k}_{\text {UNCAT }}[\mathrm{AT}]_{\mathrm{O}}+\mathrm{k}_{\mathrm{ECS}}[\mathrm{AT}: \mathrm{ECS}]_{\mathrm{O}}\right)$ and absence $\left(\mathrm{T}_{1}, \mathrm{k}_{\mathrm{OBS}}=\mathrm{k}_{\mathrm{UNCAT}}\right.$ $[A T]_{0}$ ) of ECS where $T_{O}$ is the initial activity of the enzyme.), wherein $T_{1}$ and $T_{2}$ are the residual factor $X a$ activities in the absence and presence of the activator, respectively, at time for a fixed antithrombin concentration. $K_{D}$ is the equilibrium dissociation constant of antithrombin-sulfated flavanoid interaction at $\mathrm{pH} 6.0$.

$$
\begin{array}{r}
\frac{\ln \left(\mathrm{T}_{1} / \mathrm{T}_{2}\right)}{\mathrm{t}}=\mathrm{k}_{\mathrm{ACT}} \times\left[\left([\mathrm{AT}]_{\mathrm{O}}+[\mathrm{ACT}]_{\mathrm{O}}+\mathrm{K}_{\mathrm{D}}\right)-\left\{\left([\mathrm{AT}]_{\mathrm{O}}+\right.\right.\right. \\
\left.\left.\left.[\mathrm{ACT}]_{\mathrm{O}}+\mathrm{K}_{\mathrm{D}}\right)^{2}-4[\mathrm{AT}]_{\mathrm{O}}[\mathrm{ACT}]_{\mathrm{O}}\right\}^{1 / 2}\right] / 2[\mathrm{AT}]_{\mathrm{O}}
\end{array}
$$

The antithrombin inhibition of factor $\mathrm{Xa}$ in the presence of both CS and EFGH" was measured in pH 6.0, I 0.025 buffer at $25{ }^{\circ} \mathrm{C}$. A fixed $10 \mathrm{nM}$ concentration of factor $\mathrm{Xa}$ was incubated with $0.5 \mu \mathrm{M}$ antithrombin in the presence of $50 \mu \mathrm{M}$ $\mathrm{CS}$ and either 1,2 , or $4 \mu \mathrm{M} \mathrm{EFGH}$ ". Aliquots were withdrawn at defined time points, and the residual active enzyme concentration was determined by following the amidolysis of $100 \mu \mathrm{M}$ Spectrozyme fXa substrate in $20 \mathrm{mM}$ sodium phosphate buffer, $\mathrm{pH}$ 7.4, containing $100 \mathrm{mM} \mathrm{NaCl}$ and $0.1 \%$ PEG8000, at $25{ }^{\circ} \mathrm{C}$. The spectrophotometrically determined initial slope $\left(\lambda_{\operatorname{MAx}}=405 \mathrm{~nm}\right)$ of the hydrolysis was plotted against the incubation time, and the data fit to an exponential decay equation to obtain the observed rate constant of the reaction.

\section{Results}

Equilibrium Dissociation Constant of Antithrombin Interactions with Sulfated Flavanoids. Our previous molecular modeling study using HINT suggested that rationally designed ECS may bind in the PBS of antithrombin. ${ }^{20}$ Nearly all positively charged residues in the binding domain that interact with trisaccharide DEF were found to interact favorably with ECS. The overall HINT score for ECS-antithrombin complex was 3687 suggesting a high-affinity interaction. ${ }^{20}$ Changing the orientation of one group, either the 3-O-sulfate group ((+)-CS) or the aryl group ((-)-CS), resulted in comparable overall HINT scores of 3556 and 3692 for the antithrombin complexes (Table 1). (+)-CS and (-)-CS are diastereoisomers of ECS (Figure 1) representing significant alteration in the structure of the rationally designed lead molecule. The predicted similarity of the overall HINT scores for the three molecules binding in the PBS was intriguing and arises from the change in the preferred conformation of the heterocyclic ring due to the change in the orientation of the substituents (not shown). ECS and CS were synthesized from commercially available (-)-epicatechin and $(+)$-catechin and purified using standard techniques. Because synthesis of (-)-CS is involved, racemic RCS was studied.

The intrinsic protein fluorescence of antithrombin increases $\sim 30 \%$ when activated by pentasaccharide DEFGH or trisaccharide DEF, affording a convenient probe for the determination of the $K_{D}$ of the interaction. ${ }^{18,19}$ The fluorescence emission spectrum of ECS, CS, and RCS exhibits significant fluorescence in the region of $310-340 \mathrm{~nm}$ (not shown) that is amplified in the presence of antithrombin suggesting that intrinsic protein fluorescence may not be appropriate to monitor the binding of these sulfated flavanoids. Hence, a nonspecific probe, TNS, was used to determine the equilibrium dissociation constant of interaction, as previously used for heparin-antithrombin and pentasaccharide-antithrombin interactions. ${ }^{31}$ 


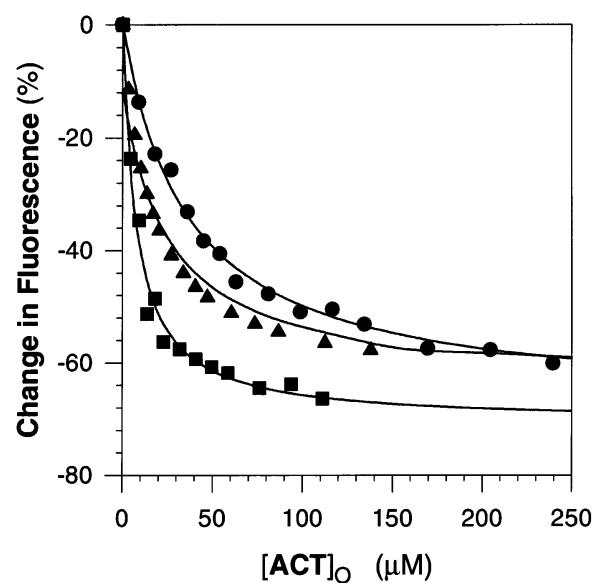

Figure 2. Interaction of ECS, CS, and RCS with plasma antithrombin. The decrease in fluorescence of the bound TNS, a nonspecific fluorescent probe, following the interaction of $\operatorname{ECS}(\boldsymbol{\Delta}), \operatorname{CS}(\boldsymbol{\nabla})$, and RCS (ब) with plasma antithrombin at $\mathrm{pH} 6.0, \mathrm{I} 0.025,25^{\circ} \mathrm{C}$, was used to determine the affinity of the sulfated flavanoids. The solid lines represent nonlinear regression fits of the data to obtain the $K_{D}$ of interaction (see Table 1).

The fluorescence of the antithrombin-TNS complex decreased as a function of the sulfated flavanoid concentration. An equivalent limiting decrease of $\sim 60-68 \%$ was obtained for all three flavanoids (Figure 2); however, the concentrations at which the maximal decrease was obtained were different for all three molecules indicating differences in their binding affinities. Equilibrium dissociation constants $\left(K_{D}\right)$ of $10.7 \pm 2.1,3.5 \pm$ 0.9 , and $26.1 \pm 3.2 \mu \mathrm{M}$ for interactions of ECS, CS, and RCS, respectively, at pH 6.0, I 0.025, were obtained by fitting the data to the quadratic binding eq II assuming a 1:1 binding stoichiometry (Table 1). These correspond to binding energies of $6.8 \pm 0.2,7.5 \pm 0.3$, and $6.3 \pm$ $0.1 \mathrm{kcal} / \mathrm{mol}$, respectively. Equivalent decrease, $\sim 65-$ $69 \%$, in TNS fluorescence was observed for ECS and CS interactions at $\mathrm{pH} 7.4, \mathrm{I} 0.035,25^{\circ} \mathrm{C}$, corresponding to $\mathrm{K}_{\mathrm{D}}$ values of $32.3 \pm 6.6$ and $17.9 \pm 3.1 \mu \mathrm{M}\left(\Delta \mathrm{G}^{\circ}=6.2\right.$ \pm 0.2 and $6.5 \pm 0.2 \mathrm{kcal} / \mathrm{mol}$ ), respectively. The decrease in binding affinities of the sulfated flavanoids at $\mathrm{pH} 7.4$ in comparison to that at $\mathrm{pH} 6.0$ is similar to the observations with sulfated ol igosaccharides, ${ }^{20}$ although the extent of the change is significantly lower for the synthetic nonsaccharide molecules.

Accelerating Effect of Sulfated Flavanoids on Factor Xa Inhibition by Antithrombin. The secondorder rate constant for uncatalyzed inhibition of factor Xa by antithrombin (KUNCAT) was determined at pH 6.0, I 0.025 , as previously described (not shown). ${ }^{18,19} \mathrm{~A}$ KUNCAT value of $325 \pm 25 \mathrm{M}^{-1} \mathrm{~s}^{-1}$ was obtained, which is approximately 3 -fold higher than our previous result. ${ }^{18}$ It is likely that this difference originates from the differences in the preparations of human factor $\mathrm{Xa}$. In our current study, we utilized human factor Xa from a commercial source, while our earlier enzyme was prepared in the laboratory. Comparative studies for the inhibition of factor $\mathrm{Xa}$ by antithrombin alone (basal inhibition, KUNCAT) and in the presence of previously well-studied saccharide ligands (accel erated inhibition, $\mathrm{k}_{\mathrm{ACT}}$ ) indicated that only the basal antithrombin inhibition rates had been affected (not shown).

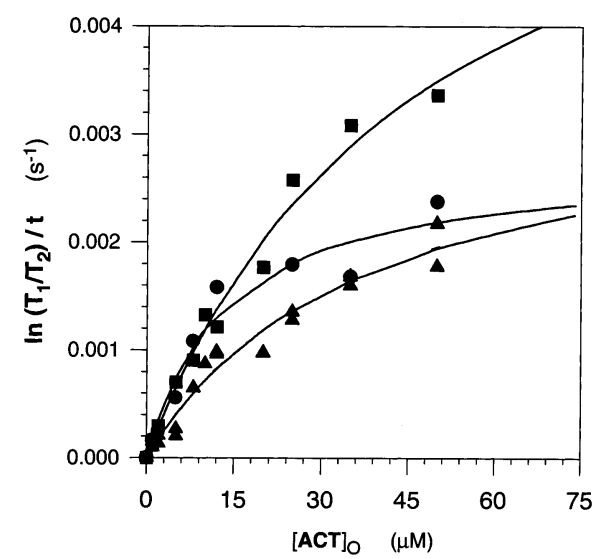

Figure 3. Accelerated inhibition of factor Xa with antithrombin in the presence of ECS, CS, and RCS. The inhibition of factor $\mathrm{Xa}(10 \mathrm{nM})$ by plasma antithrombin $(1 \mu \mathrm{M})$ in the presence of increasing concentrations $(0-50 \mu \mathrm{M})$ of ECS $(\mathbf{\Delta})$, CS $(\square)$, or RCS $(\bullet)$ was monitored from the decrease in the concentration of residual active enzyme under pseudo-firstorder conditions at $\mathrm{pH} 6.0, \mathrm{I} 0.025,25^{\circ} \mathrm{C}$. A composite analysis in the absence $\left(T_{1}\right)$ and presence $\left(T_{2}\right)$ of the sulfated activator at a fixed time point (t) was used to determine second-order rate constant of inhibition $\mathrm{K}_{\mathrm{ACT}}$. Solid lines represent nonlinear regressions of the data to eq IV. See Materials and Methods.

The second-order rate constant for the accelerated inhibition of factor $X a$ by antithrombin-sulfated flavanoid complex $\left(\mathrm{k}_{\mathrm{ACT}}\right)$ was evaluated from the residual factor Xa activity of reactions with increasing concentrations of the sulfated flavanoid reaching greater than $80 \%$ saturation of the inhibitor. The concentration dependence profiles of factor $\mathrm{Xa}$ inhibition at $\mathrm{pH}$ 6.0, I $0.025,25^{\circ} \mathrm{C}$, is shown in Figure 3 . The profiles indicate significant differences in the acceleration potential of each sulfated flavanoid. Analysis of the data using eq III gives second-order rate constants $\left(\mathrm{k}_{\mathrm{ACT}}\right)$ of $3380 \pm$ $215,6750 \pm 475$, and $2770 \pm 170 \mathrm{M}^{-1} \mathrm{~s}^{-1}$ for ECS, CS, and RCS, respectively. Thus, the second-order rate constant of antithrombin inhibition of factor $\mathrm{Xa}$ increased $10.4 \pm 1.5$-, $20.8 \pm 3.1$-, and $8.5 \pm 1.2$-fold in the presence of ECS, CS, and RCS, respectively (Table 1).

Resolution of the Ionic and Nonionic Free Energy of Binding in the Interaction. To determine the nature of interactions made by the sulfated flavanoids with plasma antithrombin, the dissociation constant was measured $\left(\mathrm{K}_{\mathrm{D}, \mathrm{OBS}}\right)$ as a function of $\mathrm{NaCl}$ concentration. The $\log K_{D, O B S}$ increased linearly with $\log \left[\mathrm{Na}^{+}\right]$at $\mathrm{pH} 7.4$ and at pH 6.0 (Figure 4), similar to the interaction of heparin with antithrombin..$^{8,18,19}$ According to the protein-polyelectrolyte theory, $8,29,32$ the number of ionpair interactions $(Z$, Table 2$)$ involved in binding, and hence the binding energy due to ionic forces $\left(\Delta G_{\text {IONIC }}^{\circ}\right)$ and the binding energy due to nonionic forces $\left(\Delta \mathrm{G}_{\mathrm{NONIONIC}}^{\circ}\right)$ can be obtained from the slope and intercept, respectively, of the linear plot.

The slopes of these lines indicated that $1.2 \pm 0.2,1.9$ \pm 0.3 , and $1.0 \pm 0.3$ ion-pair interactions are made by ECS, CS, and RCS, respectively, at pH 6.0 (Table 2). Thus, CS in comparison to ECS makes an additional charge-charge interaction, while RCS, the racemic mixture, forms only one ionic interaction. These interactions result in binding energy contributions due to ionic forces of 2.1, 3.4, and $1.7 \mathrm{kcal} / \mathrm{mol}$ at $\mathrm{pH} 6.0$ for ECS, 


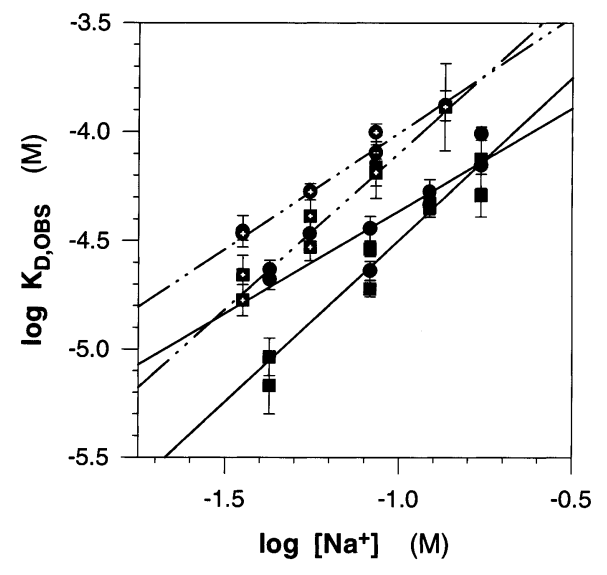

Figure 4. Dependence of the observed dissociation constant of ECS (ט) and CS (ם) interactions with antithrombin on the ionic strength of the medium. The ionic strength of the medium was varied by increasing the $\mathrm{NaCl}$ concentration in the $\mathrm{pH}$ 6.0 (solid symbols, -) and 7.4 (symbols with + mark, - - -) buffers at $25{ }^{\circ} \mathrm{C}$. Lines represent linear regression fits of the data to eq III. The slope corresponds to the number of ionpair interactions while the intercept provides the contribution of the nonionic interactions to the total binding energy. See Table 2 and Materials and Methods for details.

$\mathrm{CS}$, and RCS, respectively. At $\mathrm{pH} 7.4$, the number of ion-pair interactions, and hence the $\Delta G_{\text {IONIC }}^{\circ}$ made by ECS and CS, $1.3 \pm 0.2$ and $1.8 \pm 0.2$, respectively, remain nearly identical to that at $\mathrm{pH} 6.0$ (Table 1 ).

The intercepts ( $\left.\log K_{D, N O N I O N I C}\right)$ of the linear plots gave values of $-3.4 \pm 0.1,-3.0 \pm 0.3$, and $-3.3 \pm 0.3$ at $\mathrm{pH} 6.0$ for ECS, CS, and RCS, respectively, corresponding to an equilibrium dissociation constant due to nonionic forces ( $\left.K_{D, N O N I O N I C}\right)$ of $0.4 \pm 0.1,1.0 \pm 0.2$, and $0.5 \pm 0.2 \mathrm{mM}$, respectively (Table 1 ). These interactions result in free energy of binding due to nonionic interactions of $4.7,4.1$, and $4.6 \mathrm{kcal} / \mathrm{mol}$ for ECS, CS, and RCS, respectively. The intercepts at $\mathrm{pH} 7.4$ decrease to -3.9 \pm 0.2 and $-3.7 \pm 0.2$ for $\mathrm{ECS}$ and $\mathrm{CS}$, respectively, corresponding to $K_{D, N O N I O N I C}$ of $1.1 \pm 0.2$ and $2.2 \pm 0.4$ $\mathrm{mM}$ and a $\Delta \mathrm{G}_{\mathrm{NONIONIC}}^{\circ}$ of 4.1 and $3.6 \mathrm{kcal} / \mathrm{mol}$, respectively. Thus, binding affinity due to nonionic forces is 2-fold higher for ECS than for CS under both $\mathrm{pH}$ conditions.

Equilibrium Binding of CS with Antithrombin in the Presence of Tetrasaccharide EFGH". To determine whether our designed activators bind antithrombin in the PBS as predicted, we studied the interaction of CS, the sulfated flavanoid with highest affinity and activation potential among the three studied, in the presence of tetrasaccharide EFGH". Previously, we have shown that saccharide activator EFGH" binds $(6.9 \pm 1.3 \mu \mathrm{M})$ in the pentasaccharide binding domain and fully activates ( $280 \pm 30$-fold) plasma antithrombin at both $\mathrm{pH} 6.0$ and $\mathrm{pH} 7.4 .^{18}$ Thus, if CS interacts with the PBS in antithrombin, it is expected to compete with tetrasaccharide EF GH" in a predictable competitive manner.

The binding of EFGH" alone to antithrombin leads to $\sim 43 \%$ decrease in TNS fluorescence at $\mathrm{pH} 6.0, \mathrm{I}$ 0.025, $25{ }^{\circ} \mathrm{C}$, similar to the $\sim 60-70 \%$ decrease observed for CS alone. Fitting the data (not shown) to the quadratic binding equation leads to an equilibrium dissociation constant $\left(\mathrm{K}_{\mathrm{EFGH}}\right)$ ) of the interaction of $4.5 \pm 0.2 \mu \mathrm{M}$, which is equivalent to that determined previously from the $\sim 30 \%$ increase in intrinsic protein fluorescence. ${ }^{18}$ The binding of CS to plasma antithrombin in the presence of EFGH" was monitored by the decrease in fluorescence of the bound TNS. In the presence of a fixed 3.0-30 $\mu \mathrm{M} \mathrm{EFGH"} \mathrm{(0.67-6.7} \mathrm{×} \mathrm{KEFGH"),} \mathrm{the} \mathrm{apparent}$ dissociation constant of the CS-antithrombin interaction ( $\left.K_{C S, A P P}\right)$ under these conditions did not change appreciably from its value of $3.5 \mu \mathrm{M}$ in the absence of tetrasaccharideEFGH" (Table 3). Assuming competitive binding, the $K_{\text {CS,APP }}$ is expected to increase from 5.8 to $26.8 \mu \mathrm{M}$, a $\sim 7.7$-fold increase over the $\mathrm{K}_{\mathrm{CS}}$.

The maximal change in TNS fluorescence in each case was found to be in the range of $\sim 60-70 \%$, identical to that observed in the absence of tetrasaccharide EF GH". At the same time, the decrease in TNS fluorescence due to EFGH" in each experiment increased as a function of the added tetrasaccharide reaching a maximal value of $\sim 43 \%$ at the highest concentrations of EFGH" (Table 3). This indicates a proportional increase in the EFGH"antithrombin complex with the added tetrasaccharide and equivalent to that observed in independent experiments. These results suggest that although the presence of tetrasaccharide EFGH" results in the formation of its complex with antithrombin, the $\mathrm{K}_{\mathrm{CS} \text {,APP }}$ is not affected.

Kinetics of Antithrombin Inhibition of Factor $\mathrm{Xa}$ in the Presence of CS and Tetrasaccharide EF GH". To further investigate whether CS competes with EFGH" in the phenomenon of antithrombin activation, we determined the kinetics of factor $\mathrm{Xa}$ inhibition at $\mathrm{pH} 6.0, \mathrm{I} 0.025,25{ }^{\circ} \mathrm{C}$. The antithrombin inhibition of factor $\mathrm{Xa}$ in the presence or absence of CS and EFGH" was determined by measuring the residual factor Xa activity at defined incubation time points. The observed rate constant ( $\mathrm{K}_{\mathrm{OBS}}$ ) of factor $\mathrm{Xa}$ inhibition increased from $(0.08 \pm 0.01) \times 10^{-3} \mathrm{~s}^{-1}$ for $0.26 \mu \mathrm{M}$ plasma antithrombin alone to $(2.0 \pm 0.4) \times 10^{-3} \mathrm{~s}^{-1}$ in the presence of $50 \mu \mathrm{M} \mathrm{CS}$, as expected on the basis of the measured kunCAT and $k_{C S}$ values (Table 1 ). With 1 $\mu \mathrm{M} \mathrm{EFGH"} \mathrm{and} 50 \mu \mathrm{M} \mathrm{CS}$, the koBs value of $0.26 \mu \mathrm{M}$ antithrombin inhibition of factor Xa increased further to $(4.3 \pm 0.7) \times 10^{-3} \mathrm{~s}^{-1}$, a gain of 2.2 -fold (Figure 5 ). The observed rate constant increased 2.4- and 3.7-fold as the concentration of EFGH" was increased to 2 and $4 \mu \mathrm{M}$, respectively, in incubations of $0.26 \mu \mathrm{M}$ antithrombin and $50 \mu \mathrm{M}$ CS with factor $\mathrm{Xa}$.

Assuming competitive inhibition, in accordance with the Dixon-Webb relationship, the koвs values are expected to increase to $1.9 \times 10^{-3}, 2.1 \times 10^{-3}$, and 2.5 $\times 10^{-3} \mathrm{~s}^{-1}$ with 1,2 , and $4 \mu \mathrm{M} E F H^{\prime \prime}$, respectively, representing increases of only 1.01-, 1.23-, and 1.47-fold under identical conditions (F igure 5). Thus, the presence of an excess of CS is not able to negate the effect of accelerated antithrombin inhibition of factor $\mathrm{Xa}$ by much lower concentrations of EFGH". On the contrary, assuming that the two activators bind independently but not simultaneously, pseudo-first-order rate constants of factor $\mathrm{Xa}$ inhibition $\left(\mathrm{k}_{I N}\right)$ at 1,2 , and $4 \mu \mathrm{M}$ $\mathrm{EFGH}^{\prime \prime}$ are expected to be $4.4 \times 10^{-3}, 6.3 \times 10^{-3}$, and $8.7 \times 10^{-3} \mathrm{~s}^{-1}$, respectively. These enhancements of 2.6-, 3.7-, and 5.1-fold, respectively, correlate well with the observed increases noted above. Thus, the activation properties of CS in the presence of EFGH" more cl osely 
Table 2. I onic and Nonionic Components of the Observed Free Energy of Binding for the Interaction of Sulfated Flavanoids with Plasma Antithrombina

\begin{tabular}{|c|c|c|c|c|c|c|c|c|}
\hline & \multicolumn{2}{|c|}{$\mathrm{K}_{\mathrm{D}, \mathrm{NONIONIC}}(\mathrm{mM})$} & \multicolumn{2}{|c|}{$\Delta \mathrm{G}_{\mathrm{NONIONIC}}^{\circ}(\mathrm{kcal} / \mathrm{mol})$} & \multicolumn{2}{|c|}{ Z } & \multicolumn{2}{|c|}{$\Delta \mathrm{G}_{\text {IONIC }}^{\circ}(\mathrm{kcal} / \mathrm{mol})$} \\
\hline & $\mathrm{pH} 6.0$ & $\mathrm{pH} 7.4$ & $\mathrm{pH} 6.0$ & $\mathrm{pH} 7.4$ & $\mathrm{pH} 6.0$ & $\mathrm{pH} 7.4$ & $\mathrm{pH} 6.0$ & $\mathrm{pH} 7.4$ \\
\hline $\begin{array}{l}(-) \text {-ECS } \\
(+)-C S \\
( \pm)-C S\end{array}$ & $\begin{array}{c}0.38 \pm 0.05 \\
1.0 \pm 0.2 \\
0.47 \pm 0.15\end{array}$ & $\begin{array}{l}1.1 \pm 0.2 \\
2.2 \pm 0.4\end{array}$ & $\begin{array}{l}4.7 \pm 0.1 \\
4.1 \pm 0.2 \\
4.6 \pm 0.3\end{array}$ & $\begin{array}{l}4.1 \pm 0.2 \\
3.6 \pm 0.2\end{array}$ & $\begin{array}{l}1.18 \pm 0.19 \\
1.86 \pm 0.30 \\
0.95 \pm 0.30\end{array}$ & $\begin{array}{l}1.34 \pm 0.19 \\
1.80 \pm 0.19\end{array}$ & $\begin{array}{l}2.14 \pm 0.19 \\
3.37 \pm 0.30 \\
1.72 \pm 0.30\end{array}$ & $\begin{array}{l}2.13 \pm 0.19 \\
2.87 \pm 0.19\end{array}$ \\
\hline
\end{tabular}

a The dependence of $\mathrm{K}_{\mathrm{D}, \mathrm{OBS}}$ on the ionic strength $(\mathrm{I})$ at $25^{\circ} \mathrm{C}$ in $20 \mathrm{mM}$ sodium phosphate buffer at either pH 6.0 or pH $7.4 \mathrm{was}$ determined in titrations of plasma antithrombin with the activator. $\mathrm{NaCl}$ was used to increase the ionic strength of the medium. Linear regression of the data (Figure 4) gave the intercept and slope from which the ionic and nonionic components of the binding energy were calculated. Error shown represents $\pm 2 \mathrm{SE}$. See Materials and Methods.

Table 3. Effect of Tetrasaccharide EFGH" on the Binding of CS to Antithrombin ${ }^{\text {a }}$

\begin{tabular}{ccccc}
\hline $\begin{array}{c}\text { [EFGH" } \\
(\mu \mathrm{M})\end{array}$ & $\begin{array}{c}\mathrm{K}_{\mathrm{CS}, \mathrm{APP}} \\
(\mu \mathrm{M})\end{array}$ & $\begin{array}{c}\mathrm{Calcd} \mathrm{K}_{\mathrm{CS}, \mathrm{APP}} \mathrm{b} \\
(\mu \mathrm{M})\end{array}$ & $\begin{array}{c}\Delta \mathrm{F}_{\mathrm{EFGH}^{\prime \prime}} \\
(\%)\end{array}$ & $\begin{array}{c}\Delta \mathrm{F}_{\mathrm{MAX}} \\
(\%)\end{array}$ \\
\hline 0 & $3.5 \pm 0.9$ & 3.5 & & -68 \\
3.0 & $4.8 \pm 0.5$ & 5.8 & -25 & -63 \\
4.5 & $3.5 \pm 1.5$ & 7.0 & -28 & -58 \\
10 & $3.1 \pm 1.6$ & 11.2 & -37 & -62 \\
20 & $3.2 \pm 0.3$ & 19.1 & -43 & -70 \\
30 & $2.1 \pm 1.5$ & 26.8 & -41 & -69 \\
\hline
\end{tabular}

a The dependence of equilibrium dissociation constant of CSantithrombin interaction ( $\mathrm{K}_{\mathrm{CS}, \mathrm{APP}}$ ) at $25{ }^{\circ} \mathrm{C}$ in $20 \mathrm{mM}$ sodium phosphate buffer, pH 6.0, containing $20 \mathrm{mM} \mathrm{NaCl}$ on tetrasaccharide E F GH" was determined by monitoring the decrease in the fluorescence of external probe, TNS. The calculated value of the apparent equilibrium dissociation constant (calculated $\mathrm{K}_{\mathrm{CS}, \mathrm{APP}}$ ) was obtained assuming competitive binding (see below). $\Delta \mathrm{F}_{\mathrm{EFGH}}$ " is the change in fluorescence of the bound TNS on addition of the tetrasaccharide $\mathrm{FGH}^{\prime \prime}$, and $\Delta \mathrm{F}_{\mathrm{MAx}}$ represents the total decrease in fluorescence following the subsequent addition of CS. Errors shown represent \pm 1 SE. See Materials and Methods. b Calculated using Dixon-Webb relationship K KS,APP $=K_{C S}\left(1+\left[E F G H^{\prime \prime}\right]_{0} /\right.$ $\left.\mathrm{K}_{\mathrm{EFGH}}\right)^{\prime}$, where $\mathrm{K}_{\mathrm{EFGH}}$ "was found to be $4.5 \pm 0.2 \mu \mathrm{M}\left(\Delta \mathrm{F}_{\mathrm{EFGH}}{ }^{\prime \prime}=\right.$ $-43 \%$ ) in $\mathrm{pH} 6.0$ buffer containing $20 \mathrm{mM} \mathrm{NaCl}$ at $25^{\circ} \mathrm{C}$.

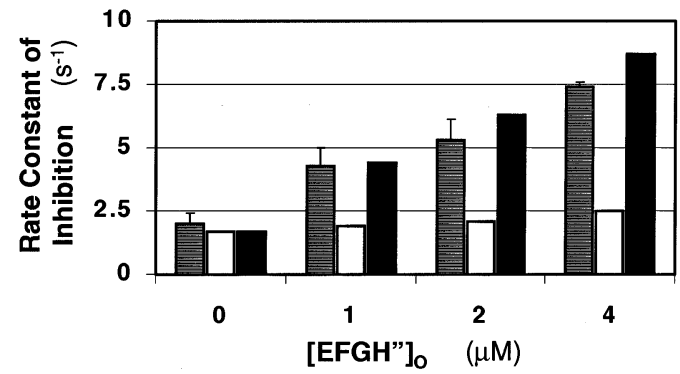

Figure 5. Effect of the heparin binding site ligand, tetrasaccharide EFGH", on the observed rate constant of factor Xa inhibition $\left(\mathrm{k}_{\mathrm{OBS}}\right)$ by antithrombin in the presence of a fixed concentration of CS. The pseudo-first-order observed rate constant ( $\mathrm{K}_{\mathrm{OBS}}$, box with solid dots) of factor $\mathrm{Xa}$ inhibition by $0.26 \mu \mathrm{M}$ plasma antithrombin and $50 \mu \mathrm{M} \mathrm{CS}$ at pH 6.0, I 0.025, $25^{\circ} \mathrm{C}$ was determined in the presence of $0,1,2$, and $4 \mu \mathrm{M}$ EFGH". Error bars represent \pm 1 SE. For comparative purposes, values of the pseudo-first-order rate constant assuming competitive inhibition ( $\mathrm{K}_{\mathrm{OBS}, \mathrm{Cl}}$, box with solid gray) and simultaneous independent inhibition ( $\mathrm{K}_{\mathrm{OBS}, \mathrm{IN}}$, box with solid black) were calculated. See Table 4 and Materials and Methods for details.

resemble interaction wherein CS does not compete with the PBS ligand, EFGH".

Equilibrium Binding of CS with Antithrombin in the Presence of LAH. To determine whether our designed molecules compete with full-length heparin, we studied the interaction of CS with antithrombin in the presence of LAH. Full-length heparin chains devoid of the high-affinity pentasaccharide sequence, called LAH chains, bind antithrombin with a 1000-fold weaker

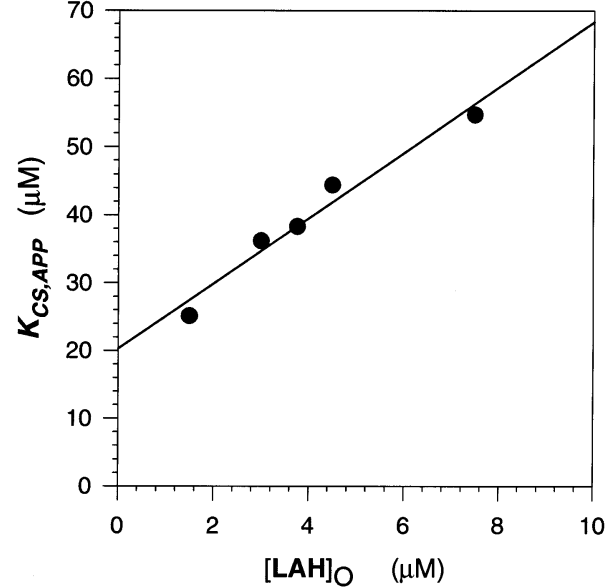

Figure 6. Effect of LAH on apparent equilibrium dissociation constant of CS interaction with plasma antithrombin (K $\mathrm{K}_{\mathrm{CS}, \mathrm{APP}}$ ). The interaction was measured by the change in fluorescence of an external probe, TNS, at $\mathrm{pH} 7.4, \mathrm{I} 0.035,25^{\circ} \mathrm{C}$, in the presence of $1.5,3.0,3.8,4.5$, and $7.5 \mu \mathrm{M}$ LAH of $\mathrm{M}_{\mathrm{R}} 7900 \pm$ $790 \mathrm{Da}$. The solid line represents linear regressional fit of the data to the Dixon-Webb competitive binding equation. See Materials and Methods and text for details.

affinity in comparison to the HAH chains containing the high-affinity sequence. ${ }^{33}$ Olson and co-workers have shown that LAH interacts with antithrombin in a manner similar to $\mathrm{HAH} .{ }^{33}$ Because the binding affinity of $\mathrm{HAH}$ is vastly different from that of $\mathrm{CS}$, we chose to use $\mathrm{LAH}$ as a competitor.

The binding of CS to plasma antithrombin in the presence of $\mathrm{LAH}$ was monitored by the decrease in fluorescence of the bound TNS. In the presence of a fixed 1.5-7.5 $\mu \mathrm{M} \mathrm{LAH}$, the apparent dissociation constant of CS-antithrombin interaction ( $\left.\mathrm{K}_{\mathrm{CS}, \mathrm{APP}}\right)$ increased linearly from 25.1 to $54.7 \mu \mathrm{M}$ (Figure 6). The linear increase in $\mathrm{K}_{\mathrm{CS}, \mathrm{APP}}$ with [LAH] $]_{\mathrm{O}}$ indicates competitive binding, as expected on the basis of the Dixon-Webb relationship. Linear regression of the plot gives an intercept of $17.6 \pm 2.2 \mu \mathrm{M}$ and a slope of $5.6 \pm 0.6$ at $\mathrm{pH} 7.4, \mathrm{I} 0.035,25^{\circ} \mathrm{C}$.

Modeling the Binding of CS at a Plausible Site Distinct from the Pentasaccharide Binding Domain on Antithrombin. To investigate whether our designed sulfated flavanoids possibly interact with the EHBS, rather than the PBS, we studied the interaction of CS using molecular docking and scoring techniques. CS was placed in the region formed by Arg132 and Arg136 residues in an arbitrary orientation, and iterative docking using Flexidock was used to perform a conformational minimum for the complex. Analysis of the 20 solutions obtained after iterative docking indi- 
Table 4. Effect of Tetrasaccharide EFGH" on the Observed Rate Constant of Accelerated Inhibition of Factor Xa by Antithrombin-CS Complex

\begin{tabular}{|c|c|c|c|c|}
\hline $\begin{array}{c}{[\mathrm{CS}]_{\mathrm{O}}} \\
(\mu \mathrm{M})\end{array}$ & $\begin{array}{c}{\left[\mathrm{EFGH}{ }^{\prime \prime}\right]_{0}} \\
(\mu \mathrm{M})\end{array}$ & $\begin{array}{c}\text { kOBS } \\
\left(10^{3} \times S^{-1}\right)\end{array}$ & $\begin{array}{c}\text { calcd }_{\mathrm{k}_{\mathrm{Cl} \text {, calcd }}{ }^{\mathrm{C}}}^{\left(10^{3} \times \mathrm{S}^{-1}\right)}\end{array}$ & $\begin{array}{c}\text { calcd }_{k_{I N}, \text { calcd }^{b}} \\
\left(10^{3} \times \mathrm{S}^{-1}\right)\end{array}$ \\
\hline 50 & 0 & $2.0 \pm 0.4$ & 1.7 & 1.7 \\
\hline 50 & 1 & $4.3 \pm 0.7$ & 1.9 & 4.4 \\
\hline 50 & 2 & $4.7 \pm 0.8$ & 2.1 & 6.3 \\
\hline 50 & 4 & $7.4 \pm 0.2$ & 2.5 & 8.7 \\
\hline 0 & 1 & $2.4 \pm 0.3$ & & \\
\hline 0 & 2 & $3.2 \pm 0.7$ & & \\
\hline 0 & 4 & $6.4 \pm 0.4$ & & \\
\hline
\end{tabular}

a The observed rate constant ( $\mathrm{K}_{\mathrm{OBS}}$ ) of factor Xa inhibition by $0.26 \mu \mathrm{M}$ antithrombin in the absence or presence of either sulfated flavanoid CS and/or tetrasaccharide EFGH" was determined in $20 \mathrm{mM}$ sodium phosphate buffer, $\mathrm{pH} 6.0$, at $25^{\circ} \mathrm{C}$. The calculated value of the observed rate constant assuming competitive inhibition ( $\left.\mathrm{K}_{\mathrm{Cl}, \mathrm{calcd}}\right)$ and independent, but not simulatenous, inhibition $\left(\mathrm{k}_{\mathrm{IN}, \text { calcd }}\right)$ was obtained by calculating the concentrations of antithrombin-CS and antithrombin-EFGH" complexes under either competitive or independent binding conditions (see bel ow, Figure 5). Errors shown represent \pm 1 SE. See Materials and Methods. ${ }^{b}$ Calculated from expression $\mathrm{k}_{\mathrm{OBS}}=\mathrm{k}_{\mathrm{UNCAT}} \times[\mathrm{AT}]_{\mathrm{O}}+\mathrm{k}_{\mathrm{ACT}, \mathrm{CS}} \times$ $[A T: C S]_{O}+k_{A C T, E F G H} \times$ [AT:EFGH"] ${ }_{0}$ where $k_{\text {UNCAT }}$ and $\mathrm{k}_{\mathrm{ACT}, \mathrm{CS}}$, determined earlier, are 325 and $6750 \mathrm{M}^{-1} \mathrm{~s}^{-1}$. Second-order rate constant $\mathrm{K}_{\mathrm{ACT}, \mathrm{EFGH}}$ " was independently determined to be 58150 $\mathrm{M}^{-1} \mathrm{~S}^{-1}$. The concentrations of complexes ([AT:CS] and [AT: $\left.\mathrm{EFGH}^{\prime \prime}\right]_{\mathrm{O}}$ ) were determined from the quadratic equilibrium binding equation. For competitive inhibition ( $\left.\mathrm{K}_{\mathrm{OBS}, \mathrm{Cl}}\right)$, the Dixon-Webb relationship $\left.K_{A P P}=K_{D} \times(1+\text { [competitor }]_{O} / K_{D \text {,competitor }}\right)$ was used in calculating the apparent dissociation constant for use in the quadratic binding equation. For $\mathrm{K}_{\mathrm{OBS}, \mathrm{IN}}$, the concentrations of complexes was calculated directly from initial concentrations of $\mathrm{AT}$, CS, and EFGH", without invoking competitive binding.

Table 5. Residue Level HINT Scores for the Interaction of CS with the Activated Form of Antithrombin in the PBS or EHBS

\begin{tabular}{lcc}
\hline & $\begin{array}{c}\text { pentasaccharide } \\
\text { binding site }\end{array}$ & $\begin{array}{c}\text { extended heparin } \\
\text { binding site }\end{array}$ \\
\hline Lys11 & 811 & \\
Ala43 & -218 & -51 \\
Asn45 & -31 & \\
Arg46 & 738 & \\
Arg47 & 1126 & \\
Lys114 & 834 & \\
Lys125 & 700 & 1786 \\
Arg129 & 76 & 957 \\
Arg132 & 24 & 583 \\
Lys133 & & 1100 \\
Lys136 & & 966 \\
Lys275 & & -348 \\
Asp278 & & -399 \\
other & $-504^{\mathrm{b}}$ & 4594 \\
total & 3556 &
\end{tabular}

a Residue level HINT scores were calculated by docking the sulfated flavanoid in either the PBS or the EHBS in the activated form of antithrombin. A positive HINT score indicates favorable interaction, while a negative score suggests unfavorable interaction. See Materials and Methods for details. $b$ This includes small contributions from Val5, Cys8, Ala10, Pro12, Asp14, Pro41, Glu42, Thr44, Val48, Ser 112, and Phe122 residues. ' This includes small contributions from Asn135, Gly276, Asp277, Glu414, Pro416, and Leu417 residues.

cated a unique family of structures with equivalent orientation and energy.

HINT analysis of the structure with the least energy (Figure 6) indicates an overall HINT score of 4594, which is higher than the score of 3556 obtained for CS binding in the pentasaccharide binding domain (Table 5). The higher HINT score indicates greater propensity for CS to interact with the EHBS. At the individual residue level, favorable interactions are observed for
Arg129, Arg132, Lys133, Lys136, and Lys275 residues with HINT scores of 1786, 957, 583, 1100, and 966, respectively. Interestingly, HINT predicts that the strength of ionic interactions for CS binding to the EHBS is weaker than those predicted for the PBS, while the strength of hydrogen-bonding interactions is reversed (not shown). These simulation results also suggest that the small designed flavanoid CS is likely to interact with positively charged residues of the EHBS.

\section{Discussion}

The phenomenon of small, organic, nonsaccharide molecule driven conformational activation of antithrombin represents a significant advance in the direction of new anticoagulation agents. The design and success of ECS, a sulfated flavanoid, represents the first such attempt. ${ }^{20}$ De novo activator ECS was designed to bind antithrombin in the PBS; yet, it proved to be a much weaker activator of antithrombin ( 10-fold) in comparison to the reference trisaccharide ( $\sim 300$-fold), on which it was based. ${ }^{20}$ To identify the reason(s) for this deficiency, the molecular nature of interactions of ECS, and related diastereoisomeric flavanoids, the catechin sulfates were studied.

The nearly identical overall HINT scores for (+)-CS and ECS interacting with the pentasaccharide binding domain suggested that the two structurally distinct, sulfated flavanoids may bind the inhibitor with equivalent affinity. However, differences of the order of 2-3fold were noted in the observed binding affinities at $\mathrm{pH}$ 6.0 and 7.4 (Table 1). For the racemic mixture, $( \pm)$-CS, the free energy of binding decreased nearly $1.2 \mathrm{kcal} /$ mol suggesting that the (-)-CS enantiomer had a significantly lower binding affinity than the (+)-CS isomer. Similar differences were also noted in their conformational activation properties. The rate of factor $\mathrm{Xa}$ inhibition in the presence of ECS and (+)-CS increased 10.4-20.8-fold indicating substantial activation of antithrombin (Table 1). As with the binding affinity, the acceleration observed with racemic $( \pm)$-CS decreased $\sim 2$-fold in comparison to (+)-CS suggesting that (-)-CS is a much weaker activator of antithrombin than its enantiomer. Because each activator was synthesized independently from enantiomerically pure reactants, there is no possi bility of cross-contamination of products clouding the differences observed in activities. Thus, these sulfated flavanoids form the first series of small organic activators, and not surprisingly, binding and activation of antithrombin is a function of the structure of the activator.

Assuming that conformational activation of the inhibitor can result in a 300-fold maximal increase in the second-order rate constant of factor Xa inhibition, as noted with pentasaccharide DEFGH and other saccharide ligands, 8,18,19 the acceleration observed with these sulfated flavanoids corresponds to $\sim 3.4-6.9 \%$ activation of the full possible. The interaction of these small organic molecules to antithrombin thus results in a small, but significant and measurable, change in the conformational equilibrium toward the activated form. Yet, it is intriguing that the observed activation potential is much lower than that expected on the basis of their predicted binding within the PBS.

To determine the origin of this deficiency, the ionic and nonionic components of the free energy of binding 
were resolved for three molecules. While ECS exhibits only one ion-pair interaction, (+)-CS exhibits two ionic interactions at both $\mathrm{pH} 6.0$ and pH 7.4 (Figure 3, Table 2). These ion-pair interactions are substantially lower than the 4-5 interactions observed with saccharide activators under these conditions. ${ }^{18}$ Furthermore, the number of ion-pair interactions for the sulfated flavanoids remains identical at either $\mathrm{pH}$. This observation sharply contrasts an increase of one ion-pair interaction typically observed at the lower $\mathrm{pH}$ for antithrombin binding to saccharide activators that contain residue D. 18 Thus, it is likely that the designed sulfated flavanoids do not effectively mimic the interaction with residue $D$, although the lead flavanoid ECS was rationally designed on the basis of trisaccharide DEF structure. These differences in the nature of ionic interactions suggest considerable differences in binding between the sulfated flavanoid and the saccharide activators.

Resol ution of the components of the observed binding energy suggests nearly $3.6-4.7 \mathrm{kcal} / \mathrm{mol}$ contributions due to nonionic forces. This represents a major $\sim 55-$ $73 \%$ contribution of the total binding energy (6.2-7.5 $\mathrm{kcal} / \mathrm{mol}$ ). A similar ( 40-60\%) nonionic binding energy contribution has been observed for antithrombinDEFGH interaction. ${ }^{8,18}$ Although it is likely that nonionic forces including hydrophobic interaction may play a major role in the interaction of the designed sulfated flavanoids, previous HINT analysis and biochemical studies on antithrombin interactions have suggested significant nonionic contributions by ionic interactions. ${ }^{20,34}$ The origin of the major nonionic binding energy remains unclear at the present time but highlights an important avenue for enhancing the overall binding affinity of new designed molecules.

Tetrasaccharide EFGH", lacking nonreducing end residue $D$, binds antithrombin in the pentasaccharide binding domain and induces an activating conformational change in the inhibitor ( 280 -fold) that is equivalent to pentasaccharide DEFGH. ${ }^{18}$ The absence of residue $\mathrm{D}$ in $\mathrm{EFGH}$ " is equivalent to the absence of interactions in the sulfated flavanoids that mimic residue $D$ (above). Furthermore, the antithrombin affinity of EFGH" is similar to that of the sulfated flavanoids. Thus, these characteristics make tetrasaccharide EFGH" a good probe to test whether the designed sulfated flavanoids bind antithrombin in the pentasaccharide binding domain, as predicted on the basis of HINT analysis.

Equilibrium binding in the presence of increasing concentrations of tetrasaccharide EFGH" indicates that the apparent dissociation constant of the CS-antithrombin interaction does not change appreciably from its value in the absence of the tetrasaccharide, despite a proportional increase in the concentration of the EFGH"-antithrombin complex (Table 3). Assuming competitive binding, the apparent dissociation constant is predicted to increase $\sim 7.7$-fold under these conditions. Likewise, the presence of an excess of CS is not able to off-set the acceleration in antithrombin inhibition of factor Xa achieved with small amounts of EFGH", as determined by the observed pseudo-first-order rate constant of the reaction (Table 4). While the calculated value of the pseudo-first-order rate constant assuming competitive inhibition $\left(\mathrm{k}_{\mathrm{CI}}\right.$,calcd $)$ predicts $\sim 25 \%$ increase at the highest EFGH" concentration studied, the observed rate constant (KoBs) increases $\sim 270 \%$. Assuming a model wherein EFGH" and CS bind antithrombin independently, but not simultaneously, the pseudo-firstorder rate constant $\left(\mathrm{k}_{\mathrm{IN}, \text {,alcd }}\right)$ is calculated to increase $\sim 335 \%$ (Table 4). Furthermore, the kobs values in the presence of EFGH" al one correlate well with that in the presence of CS and EFGH".

Competitive binding studies indicate that the $\mathrm{K}_{\mathrm{CS}, \mathrm{APP}}$ increases linearly with the concentration of LAH (Figure 6), as expected on the basis of the Dixon-Webb relationship. The dissociation constant of the CS-antithrombin interaction $\left(\mathrm{K}_{\mathrm{CS}}\right)$ at $\mathrm{pH} 7.4, \mathrm{I} 0.035$, calculated from the intercept of the regressional line, is found to be $17.6 \pm 2.2 \mu \mathrm{M}$, nearly equival ent to $19.6 \pm 2.5 \mu \mathrm{M}$ measured by direct titration (Figure 4, Table 2). Likewise, the dissociation constant of the $\mathrm{LAH}$-antithrombin interaction $\left(\mathrm{K}_{\mathrm{LAH}}\right)$, calculated from the ratio of the slope to intercept of the regressional line, is found to be $3.1 \pm 0.7 \mu \mathrm{M}$, similar to the value reported in the literature. ${ }^{33}$ These results indicate that $\mathrm{LAH}$ competes with CS in binding to antithrombin, and in combination with results with EFGH", suggests that CS binds in the heparin binding domain outside of the PBS.

To gain insight into the possibility of an alternative binding site, distinct from the PBS, we resorted to molecular modeling once again. The PBS, a region defined by the polypeptide $\mathrm{N}$ terminus and helices $\mathrm{A}$ and D, includes positively charged residues Arg47, Lys114, Lys125, and Arg129 (Figure 7). ${ }^{11,12}$ However, the interaction of polymeric heparin, and other saccharides longer than six residues, is known to extend beyond this binding domain. Biochemical studies indicate that the EHBS includes positively charged residues Arg132, Lys133, and Arg136 (Figure 7). ${ }^{16,35}$ These residues form a smaller el ectropositive domain than the pentasaccharide binding domain.

Docking of CS in the EHBS without any constraints led to a unique family of simulated complexes in which positively charged residues Arg129, Arg132, Lys133, Lys136, and Lys275 were found to play a major role (Figure 7B, Table 5). The overall HINT score of 4594 was higher than that noted for binding in the PBS (Table 5). More interestingly, the simulation predicts a bifacial interaction of CS with the EHBS. WhileArg129, Arg132, Lys133, and Lys136 form one face, Lys275 forms the other (Figure 7). The appropriate size of the binding site and the possibility of a bifacial interaction possibly favor CS binding in the extended heparin binding domain.

The extended heparin binding domain is involved in the conformational activation phenomenon. This region undergoes a significant change in the activation process, from a random loop conformation in native antithrombin to a helical structure in the activated form. ${ }^{36,37}$ Deletion of few residues in this region has been found to dramatically reduce the ability of an activator to activate antithrombin. ${ }^{38}$ The accel eration in antithrombin inhibition of factor Xa induced by full-length heparin is nearly 2 -fold greater than that induced by pentasaccharide DEFGH, 18 further supporting the role of the EHBS in antithrombin activation. Thus, it is not 

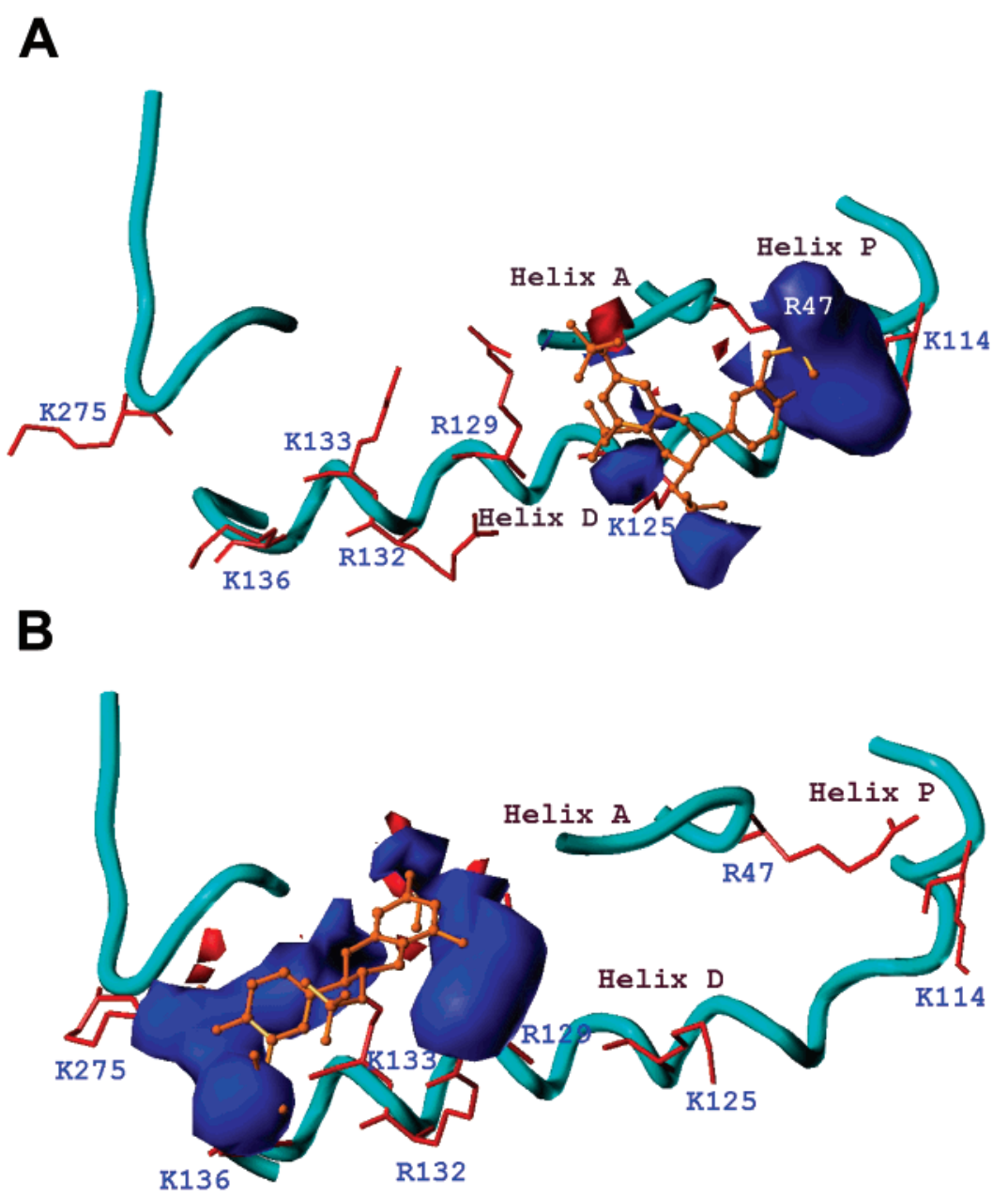

Figure 7. HINT map of CS interaction with the activated form of antithrombin in the PBS (A) and EHBS (B). CS (ochre balland-sticks) was docked onto the PBS or EHBS in the activated form of antithrombin (cyan ribbon) using Flexidock. Following minimization of the docked complexes, HINT analysis was performed to identify favorable (blue contour, positive score) and unfavorable (red contour, negative score) interactions. The PBS includes the domain formed by residues Arg47, Lys114, Lys125, and Arg129, while EHBS includes residues Arg132, Lys133, Lys136, and Lys275. Side chains of these amino acid residues are shown in red-capped sticks. See Table 5 and text for details.

surprising that small molecules binding only in the EHBS may induce conformational activation of antithrombin.

It is not immediately apparent on the basis of the HINT analyses (Table 5) the reason(s) for the sulfated flavanoids to not bind in the PBS. The PBS is approximately $16 \AA$ long, while the sulfated flavanoids are only about $8 \AA$. Further, the designed ligands do not effectively mimic residue $D$, which has previously been shown to be critical for the initial recognition of the PBS in native antithrombin. ${ }^{18}$ More importantly, a coordinated network of positively charged residues Lys114, Lys125, and Arg129 is involved in high-specificity binding of the ligands in the PBS. ${ }^{13-15}$ Together, these three residues account for nearly 3-4 critical ionic interactions. It is likely that for the cooperative network to function none of the interaction can be less than optimal.

The possibility that our small designed flavanoids do not simultaneously engage key interaction points in the PBS, e.g., Lys114 and Arg129 (Table 5), while effectively favoring bifacial interaction in the smaller extended binding site suggests that increasing the size of the activator will be helpful. A simple, but not the only, way of achieving this is to introduce $a$ one or a two carbon linker between the bicyclic and the unicyclic rings of the flavanoid framework. Rational design may then be advantageously used to identify specific molecules keeping these basic conclusions in mind.

In conclusion, although significant conformational activation of antithrombin is achieved with rationally designed sulfated flavanoids, the ligands do not bind in the PBS. Rather, the small organic activators are hypothesized to bind in the EHBS. This explains their weaker-than-expected activation of antithrombin. Further rational design of better high-affinity molecules should be attempted keeping these results in perspective.

\section{Abbreviations Used}

DEFGH, heparin pentasaccharide DEFGH; DEF, trisaccharide DEF of DEFGH; RCL, reactive center loop; HINT, hydropathic interaction analyses; ECS, (-)epicatechin sulfate; CS, (+)-catechin sulfate; $( \pm)$-CS or RCS, racemic $( \pm)$-catechin sulfate; EFGH", tetrasaccharide EFGH" resembling four residues of the pentasaccharide DEFGH; UFH, unfractionated heparin; $\mathrm{LAH}$, Iow-affinity heparin; $\mathrm{HAH}$, high-affinity heparin; $M_{R}$, average molecular weight; PBS, pentasaccharide binding site; EHBS, extended heparin binding site; $K_{D}$, 
equilibrium dissociation constant; $K_{D, N O N I O N I C}$, equilibrium dissociation constant associated with nonionic interactions only; $\Delta \mathrm{G}^{\circ}$, free energy of binding; $\Delta \mathrm{G}_{\text {IONIC }}^{\circ}$, free energy of binding due to ionic interaction only; $\Delta \mathrm{G}_{\text {NONIONIC }}^{\circ}$ free energy of binding due to nonionic interactions only; TNS, 2-(p-toluidinyl)naphthalene-6sulfonic acid; PEG, poly(ethylene glycol); RCSB, Research Collaboratory for Structural Bioinformatics.

Acknowledgment. We thank Dr. Glen Kellogg for graciously sharing his HINT program and Dr. Steven Olson for helpful discussions and for his generous gift of human antithrombin and saccharide ligands. We thank a reviewer for his important suggestion on the competitive binding experiment with full-length heparin. This work was supported by the American Heart Association (U.R.D.) and a predoctoral fellowship from AHA-Mid-Atlantic Affiliate (G.T.G.).

\section{References}

(1) Gettins, P. G. W.; Patston, P. A.; Olson, S. T. Serpins: Structure Function and Biology, R. G. Landes and Company: Austin, TX, 1996.

(2) Björk, I.; Olson, S. T. Antithrombin: A bloody important serpin. Adv. Exp. Med. Biol. 1997, 425, 17-33.

(3) Rosenberg, R. D.; Damus, P. S. The purification and mechanism of action of human antithrombin-heparin cofactor. J . Biol. Chem 1973, 248, 6490-6505.

(4) Björk, I.; Lindahl, U. Mechanism of the anticoagulant action of heparin. Mol. Cell Biochem. 1982, 48, 161-182.

(5) Choay, J .; Lormeau, J .-C.; Petitou, M.; Sinäy, P.; Fareed, J. Structural studies on a biologically active hexasaccharide obtained from heparin. Ann. N. Y. Acad. Sci. 1981, 370, 644-649.

(6) Choay, I .: Petitou, M.: Lormeau, J -C.: Sinäy, P.; Casu, B .; Gatti, G. Structure-activity relationship in heparin: a synthetic pentasaccharide with high affinity for antithrombin III and eliciting high anti-factor Xa activity. Biochem. Biophys. Res. Commun. 1983, 116, 492-499.

(7) Olson, S. T.; Srinivasan, K. R.; Björk, I.; Shore, J . D. Binding of high affinity heparin to antithrombin III: Stopped flow kinetic studies of the binding interaction. J. Biol. Chem. 1981, 256, $11073-11079$

(8) Olson, S. T.; Björk, I.; Sheffer, R.; Craig, P. A.; Shore, J. D.; Choay, J. Role of the antithrombin-binding pentasaccharide in heparin acceleration of antithrombin-proteinase reactions: Resolution of the antithrombin conformational change contribution to heparin rate enhancement. J . Biol. Chem. 1992, 267, 1252812538.

(9) Huntington, J. A.; Olson, S. T.; Fan, B.; Gettins, P. G. W. Mechanism of heparin activation of antithrombin: Evidence for reactive center loop preinsertion with expulsion upon heparin binding. Biochemistry 1996, 35, 8495-8503.

(10) Chuang, Y. J .; Swanson, R.; Raja, S. M.; Bock, S. C.; Olson, S. $T$. The antithrombin $P 1$ residue is important for target proteinase specificity but not for heparin activation of the serpin. Characterization of $\mathrm{P} 1$ antithrombin variants with altered proteinase specificity but normal heparin activation. Biochemistry 2001, 40,6670-6679.

(11) J in, L.; Abrahams, J -P.; Skinner, R.; Petitou, M.; Pike, R. N. Carrell, R. W. The anticoagulant activation of antithrombin by heparin. Proc. Natl. Acad. Sci. U.S.A. 1997, 94, 14683-14688.

(12) Ersdal-Badju, E.; Lu, A.; Zuo, Y.; Picard, V.; Bock, S. C. Identification of the antithrombin III heparin binding site. J. Biol. Chem. 1997, 272, 19393-19340.

(13) Desai, U. R.; Swanson, R. S.; Bock, S. C.; Björk, I.; Olson, S. T. The role of arginine 129 in heparin binding and activation of antithrombin. J. Biol. Chem. 2000, 275, 18976-18984.

(14) Schedin-Weiss, S.; Desai, U. R.; Bock, S. C.; Gettins, P. G. W.; Olson, S. T.; Björk, I. The importance of Iysine 125 for heparin binding and activation of antithrombin. Biochemistry 2002, 41, $4779-4788$

(15) Arocas, V.; Bock, S. C.; Raja, S.; Olson, S. T.; Björk, I. Lysine 114 of antithrombin is of crucial importance for the affinity and kinetics of heparin pentasaccharide binding. J . Biol. Chem. 2001 276, 43809-43817.

(16) Arocas, V.; Turk, B.; Bock, S. C.; Olson, S. T.; Björk, I. The region of antithrombin interacting with full-length heparin chains outside the high-affinity pentasaccharide sequence extends to Lys136 but not to Lys139. Biochemistry 2000, 39, 8512-8518.
(17) Desai, U. R.; Petitou, M.; Björk, I.; Olson, S. T. Mechanism of heparin activation of antithrombin: Role of individual residues of the pentasaccharide activating sequence in the recognition of native and activated states of antithrombin. J . Biol. Chem. 1998, 273, 7478-7487.

(18) Desai, U. R.; Petitou, M.; Björk, I.; Olson, S. T. Mechanism of heparin activation of antithrombin: Evidence for an inducedfit model of allosteric activation involving two interaction subsites. Biochemistry 1998, 37, 13033-13041.

(19) Petitou, M.; Barzu, T.; Herault, J. P.; Herbert, J. M. A unique trisaccharide sequence in heparin mediates the early step of antithrombin III activation. Glycobiology 1997, 7, 323-327.

(20) Gunnarsson, G. T.; Desai, U. R. Designing small, nonsugar activators of antithrombin using hydropathic interaction analysis. I. Med. Chem. 2002, 45, 1233-1243.

(21) van Boeckel, C. A. A.; Petitou, M. The unique antithrombin III binding domain of heparin: A lead to new synthetic antithrombotics. Angew. Chem., Int. Ed. Engl. 1993, 32, 1671-1818.

(22) Nair, V.; Bernstein, S. A convenient procedure for the preparation of triethylamine-sulfur trioxide. Orgn. Prepr. Proc. Int. Briefs 1987, 19, 466-467.

(23) Nordenman, B.; Björk, I I Influence of ionic strength and pH on the interaction between high-affinity heparin and antithrombin. Biochim. Biophys. Acta 1981, 672, 227-238.

(24) Kellogg, G. E.; J oshi, G. J .; Abraham, D. J. New tools for modeling and understanding hydrophobicity and hydrophobic interactions. Med. Chem. Res. 1992, 1, 444-453.

(25) Kellogg, G. E.; Semus, S. F.; Abraham, D. J. HINT: a new method of empirical hydrophobic field calculation for CoMFA. J . Comput.-Aided Mol. Des. 1991, 5, 545-552.

(26) Abraham, D. J .; Kellogg, G. E.; Holt, J. M.; Ackers, G. K. Hydropathic analysis of the noncovalent interactions between molecular subunits of structurally characterized hemoglobins. J . Mol. Biol. 1997, 272, 613-632.

(27) Roy, A. B. The Chemistry of sulfate esters and related compounds. In Sulfation of Drugs and Related Compounds; Mulder, G. J ., Ed.; CRC Press: Boca Raton, FL, 1981; pp 5-30.

(28) Desai, U. R.; Wang, H.-M.; Ampofo, S. A.; Linhardt, R. J. Oligosaccharide composition of heparin and low-molecularweight-heparins by capillary electrophoresis. Anal. Biochem. 1993, 213, 120-127.

(29) Olson, S. T.; Björk, I. Predominant contribution of surface approximation to the mechanism of heparin acceleration of the antithrombin-thrombin reaction: Elucidation from salt concentration effects. J. Biol. Chem. 1991, 266, 6353-6364.

(30) Olson, S. T.; Björk, I.; Shore, J . D. Kinetic characterization of heparin-catalyzed and uncatalyzed inhibition of blood coagulation proteinases by antithrombin. Methods Enzymol. 1993, 222, 525-560.

(31) Meagher, J . L.; Olson, S. T.; Gettins, P. G. W. Critical role of the linker region between helix $\mathrm{D}$ and strand $2 \mathrm{~A}$ in heparin activation of antithrombin. J. Biol. Chem. 2000, 275, 2698-2704.

(32) Mascotti, D. P.; Lohman, T. M. Thermodynamics of charged oligopeptide-heparin interactions. Biochemistry 1995, 34, 2908 2915.

(33) Streusand, V.J .; Björk, I.; Gettins, P.; Petitou, M.; Olson, S. T. Mechanism of acceleration of antithrombin-proteinase reactions by low affinity heparin: Role of the antithrombin binding pentasaccharide in heparin rate enhancement. J. Biol. Chem. 1995, 270, 9043-9051.

(34) Desai, U. R.; Gunnarsson, G. T. Hydropathic interaction analysis of the sequence-specific heparin pentasaccharide binding to antithrombin. Med. Chem. Res. 1999, 9, 643-655.

(35) Belzar, K. J .; Dafforn, T. R.; Petitou, M.; Carrell, R. W.; Huntington, J. A. The effect of a reducing-end extension on pentasaccharide binding by antithrombin. J. Biol. Chem. 2000, 275, 8733-8741.

(36) Whisstock, J .; Pike, R.; J in, L.; Skinner, R.; Pei, X.; Carrell, R.; Lesk, A. Conformational changes in serpins: II. The mechanism of activation of antithrombin by heparin. J . Mol . Biol. 2000, 301, 1287-1305.

(37) Skinner, R.; Abrahams, J .-P.; Whisstock, J . C.; Lesk, A. M.; Carrell, R. W.; Wardell, M. R. The 2.6 \& structure of antithrombin indicates a conformational change at the heparin binding site. J. Mol. Biol. 1997, 266, 601-609.

(38) Meagher, J .; Olson, S.; Gettins, P. Critical role of the linker region between helix D and strand $2 \mathrm{~A}$ in heparin activation of antithrombin. J. Biol. Chem. 2000, 275, 2698-2704.

J M020132Y 